\title{
A comparative study between ferrous carboxy maltose and iron sucrose in the management of post-partum anaemia in tertiary care hospital
}

\author{
Seeta Sunil Garag, Sanjana Kumar*
}

Department of Obstetrics and Gynecology, Karnataka Institute of Medical Sciences, Hubli, Karnataka, India

Received: 11 October 2019

Accepted: 06 November 2019

*Correspondence:

Dr. Sanjana Kumar,

E-mail: sanjanak60.sk@gmail.com

Copyright: (C) the author(s), publisher and licensee Medip Academy. This is an open-access article distributed under the terms of the Creative Commons Attribution Non-Commercial License, which permits unrestricted non-commercial use, distribution, and reproduction in any medium, provided the original work is properly cited.

\section{ABSTRACT}

Background: Anaemia is a global public health problem contributing tremendously to maternal morbidity and mortality. It is the most common indirect cause of maternal mortality. Variety of injectable iron preparations are now available which can be effective tools for combating post-partum anaemia. This study aims to compare FCM (Ferrous carboxy maltose) and iron sucrose in the treatment of iron deficiency anaemia in post-partum women at KIMS, Hubli, Karnataka, India.

Methods: This study was conducted at KIMS, Hubli in the year 2018-19 wherein 100 post-partum women with hb levels ranging from 5-10g\% were selected for the study and randomly allocated into 2 groups- FCM group and iron sucrose group. They were administered $1 \mathrm{~g}$ of FCM and $1 \mathrm{~g}$ of iron sucrose respectively after clinical evaluation and baseline measurement of $\mathrm{hb}$. They were followed up after 2 weeks for repeat $\mathrm{hb} \%$ and review of signs and symptoms. FCM and iron sucrose were compared in terms of their efficacy.

Results: The mean increase in $\mathrm{hb} \%$ was found to be $3.2 \mathrm{~g} \%$ in the FCM group and $2 \mathrm{~g} \%$ in the iron sucrose group. FCM was also found to be more efficacious in providing relief of common signs and symptoms like easy fatigability and pallor compared to iron sucrose.

Conclusions: Ferrous carboxy maltose was found to be more efficacious compared to iron sucrose.

Keywords: Anaemia, Ferrous carboxy maltose, Iron sucrose, Postpartum

\section{INTRODUCTION}

Pregnancy and puerperium are conditions that create an increased demand for nutrients in a woman's body. It is often difficult to be fulfilled by rich diet alone and makes supplementation a necessity. Anaemia is the commonest haematological disorder that may occur during pregnancy and puerperium. WHO defines anaemia as $\mathrm{Hb}<11 \mathrm{~g} \%$ in 1 st trimester, $\mathrm{Hb}<10.5 \mathrm{~g} \%$ in $2^{\text {nd }}$ and $3^{\text {rd }}$ trimesters and $\mathrm{Hb}<10 \mathrm{~g} \%$ in the postnatal period. ${ }^{1}$ It is a global public health problem and is responsible for $40 \%$ of maternal deaths in developing countries out of which it is responsible for $25 \%$ of direct maternal deaths. The prevalence of Iron deficiency anaemia (IDA) in pregnancy in India ranges from $23.6 \%-61.4 \% .^{2}$ India alone contributes $50 \%$ of global maternal deaths due to anemia. ${ }^{3}$ It is estimated that in India $50 \%$ of population suffering from anemia. About 20-40\% of maternal deaths in India are due to anemia and one in every 2 Indian women (56\%) suffers from some form of anaemia. ${ }^{4} \mathrm{It}$ contributes heavily to maternal morbidity and mortality. Anaemia is the most common indirect cause of maternal mortality.

The major causes of anaemia in the postnatal period are lack of iron supplementation during pregnancy and postpartum haemorrhage. ${ }^{5}$ Women with iron deficiency anaemia especially during the $3^{\text {rd }}$ trimester of pregnancy 
are more likely to suffer from postpartum anaemia. On the other hand, anaemia increases the risk of PPH in these women. The other risk factors identified to be associated with postpartum anaemia are multiparity, multiple pregnancy and closely spaced pregnancies. All these conditions Intern increase the risk of PPH making it a vicious cycle.

Some of the common complications of post-partum anaemia are puerperal sepsis, surgical site infection, delayed wound healing post cesarean section, subinvolution, poor lactation; others being puerperal venous thrombosis, pulmonary embolism. The traditional treatment for post-partum anaemia is oral iron supplementation while blood transfusion is reserved for more severe cases of anaemia. High doses of oral iron usually cause side effects including constipation, nausea, gastric irritation which affect compliance. Also, oral iron is often not capable of replenishing severe iron deficits. In inflammatory states, upregulation of hepcidin causes poor intestinal absorption of iron. ${ }^{6}$

Parenteral iron therapy is effective alternative to oral iron. The intramuscular iron formulation is available but complications like pain, skin discolouration, abscess formation, allergic reaction, fever, lymphadenopathy and rarerly anaphylaxis limits its use. Iron sucrose is widely being used all over the world with a good safety profile in pregnancy. ${ }^{7}$ Main disadvantage of intravenous (IV) iron sucrose is that it cannot be administered in a higher dose because of the risk of toxicity associated, thus requiring frequent visits to the hospital which puts a heavy burden on the hospital resources.

Intravenous ferric carboxy maltose is a novel iron complex which consists of a ferric hydroxide core stabilized by a carbohydrate shell. Its properties like near neutral $\mathrm{pH}$, physiological osmolarity and increased bioavailability permit the administration of large doses (15 mg/kg; maximum of $1000 \mathrm{mg} /$ infusion) in a single and rapid session (15-minute infusion) without the requirement of a test dose. $^{8}$ It has a very low immunogenic potential and therefore not predisposed to anaphylactic reactions. This study is devised to measure and compare the average increase in $\mathrm{Hb} \%$ and clinical improvement following FCM and Iron sucrose infusion in postpartum women with Iron deficiency anaemia.

\section{Objective of the study were;}

- To assess the average increase in hb\% from the baseline following $1 \mathrm{~g}$ FCM infusion in postpartum women with IDA

- To assess the average increase in $\mathrm{hb} \%$ from the baseline following $1 \mathrm{~g}$ Iron sucrose infusion in postpartum women with IDA

- To compare the efficacy of FCM with iron sucrose in terms of increase in $\mathrm{hb} \%$ and clinical improvement.

\section{METHODS}

A prospective clinical study (experimental) conducted at KIMS, Hubli, Karnataka, India. A total 100 women with post-partum anaemia included in this study. The duration of this study was 1 year (May 2018 to April 2019).

\section{Inclusion criteria}

Women admitted in the postnatal ward at KIMS, Hubli < 6 weeks after delivery with postpartum anaemia i.e, local laboratory $\mathrm{hb}>5 \mathrm{~g} \%$ and $<10 \mathrm{~g} \%$ with microcytic hypochromic blood picture.

\section{Exclusion criteria}

- Women who do not give consent for the study

- Anaemia other than due to iron deficiency or increased blood loss at the time of delivery

- Women on myelosuppressive treatment

- Women with history of bleeding disorders and haemoglobinopathies

- H/o vaginal bleed > $1000 \mathrm{ml}$ in the last 24 hours prior to enrolment

- Women who have received blood transfusion or erythropoietin in the last 3 months before screening

- Women with chronic diseases

- Women with history of reactions to injectable iron preparations.

If any subject required additional intervention like oral iron, other IV or IM preparations, blood transfusion, erythropoietin, they were considered as study drop out.

\section{Methods of data collection}

\section{History}

Demographic data of the patient like age, qualification, occupation; complaints/symptomatology, obstetric history, past menstrual history H/o chronic diseases, bleeding disorders, haemoglobinopathies, myelosuppressive treatment, recent blood transfusion (to apply the exclusion criteria).

\section{Clinical examination}

General appearance, pallor, nail and skin changes (general physical examination) followed by systemic examination.

\section{Investigations}

Baseline $\mathrm{hb} \%$ and peripheral smear

$$
\begin{array}{c|c}
\text { Infusion of FCM/ } \\
\text { Iron sucrose (1g) }
\end{array}
$$


(Note: serum ferritin was not considered as it gets altered due to inflammation especially in post LSCS patients)

\section{Intervention}

The study population was divided randomly into 2 groups:

1. FCM group

2. Iron sucrose group

- The $1^{\text {st }}$ group received inj FCM $1 \mathrm{~g}$ irrespective of the grade of anaemia (1000 mg in $200 \mathrm{ml}$ of NS over $20 \mathrm{~min}$ )

- The $2^{\text {nd }}$ group received inj Iron sucrose $1 \mathrm{~g}$ irrespective of the grade of anaemia $(200 \mathrm{mg}$ in $200 \mathrm{ml}$ of NS over $15 \mathrm{~min}-5$ doses on alternate days).

The two study groups were compared in terms of:

- Average increase in hb\% over 2 weeks

- Clinical improvement over 2 weeks.

\section{Statistical analysis}

The categorical data was expressed in terms of frequencies and percentages while continuous data was expressed as mean \pm standard deviation (SD). The two groups were compared using chisquare test for categorical data and independent sample ' $t$ ' test was used to compare the means of different parameters. A ' $p$ ' value of less than or equal to 0.05 was considered as statistically significant.

\section{RESULTS}

The study comprised of women in the reproductive age group with maximum frequency in the age group 23-27 years $(56 \%)$ followed by $18-22$ years.

About half of them were home makers and half of them unskilled labourers.

The study population comprised of mostly women with parity $2(42 \%)$.

Table 1: Socio-demographic profile.

\begin{tabular}{|lll|}
\hline Demographic & Frequency & Percentage (\%) \\
\hline Age group (years) & & \\
\hline $18-22$ & 38 & 38 \\
\hline $23-27$ & 56 & 56 \\
\hline $28-32$ & 4 & 4 \\
\hline$>32$ & 2 & 2 \\
\hline Occupation & & \\
\hline House wife & 49 & 49 \\
\hline Unskilled labour & 44 & 44 \\
\hline Skilled labour & 7 & 7 \\
\hline
\end{tabular}

Table 2: Obstetric profile.

\begin{tabular}{|lll|}
\hline Parity & Frequency & Percentage $(\%)$ \\
\hline Para 1 & 30 & 30 \\
\hline Para 2 & 42 & 42 \\
\hline Para $>/=3$ & 28 & 28 \\
\hline
\end{tabular}

Table 3: Grading of anaemia by laboratory values.

\begin{tabular}{|lll|}
\hline Grade & Frequency & Percentage (\%) \\
\hline Mild & 16 & 16 \\
\hline Moderate & 46 & 46 \\
\hline Severe & 38 & 38 \\
\hline
\end{tabular}

Considering laboratory $\mathrm{Hb}$ values, about half (46\%) of the study subjects fell under the category of moderate anaemia and $38 \%$ were severely anaemic.

Table 4: Clinical features.

\begin{tabular}{|lll|}
\hline Symptoms & Frequency & Percentage (\%) \\
\hline Asymptomatic & 34 & 34 \\
\hline Easy fatigability & 44 & 44 \\
\hline Headache & 18 & 18 \\
\hline Giddiness & 12 & 12 \\
\hline Loss of appetite & 14 & 14 \\
\hline $\begin{array}{l}\text { Breathlessness/ } \\
\text { palpitations }\end{array}$ & 5 & 5 \\
\hline
\end{tabular}

About half of the study population complained of easy fatigability and generalised weakness (44\%). About $34 \%$ of them were asymptomatic (mostly those with mildmoderate anaemia).

Table 5: Sign.

\begin{tabular}{|ll|l|}
\hline Signs & Frequency & Percentage (\%) \\
\hline Conjunctival pallor & 78 & 78 \\
\hline Pale tongue & 84 & 84 \\
\hline Facial pallor & 31 & 31 \\
\hline Pale palmar creases & 28 & 28 \\
\hline Nail changes & 42 & 42 \\
\hline Skin changes & 7 & 7 \\
\hline Tachycardia & 28 & 28 \\
\hline Cardiac murmur & 2 & 2 \\
\hline
\end{tabular}

Conjunctival pallor and pale tongue were evident in about $80 \%$ of the cases. Nail changes (mostly loss of convexity with longitudinal ridges) were seen in about half of the cases $(42 \%)$.

The pre-infusion mean hb were $7.2 \mathrm{~g} \%$ and $7.4 \mathrm{~g} \%$ in the FCM and iron sucrose groups respectively, the two groups being comparable $(\mathrm{p}>0.05)$. The average increase in laboratory haemoglobin was found to be 3.2 $\mathrm{g} \%$ in the FCM group and $2 \mathrm{~g} \%$ in the iron sucrose group. On applying tests of significance, this was found to be statistically very significant $(\mathrm{p}<0.001)$. 
Table 6: Average increase in $\mathrm{HB} \%$.

\begin{tabular}{|lll|}
\hline Average HIB (g\%) & $\begin{array}{l}\text { FCM } \\
\text { group }\end{array}$ & Iron sucrose group \\
\hline Pre-infusion & 7.2 & 7.4 \\
\hline Post-infusion & 10.4 & 9.4 \\
\hline Increase & 3.2 & 2 \\
\hline
\end{tabular}

A better improvement in $\mathrm{hb} \%$ from the base line was observed in patients with severe anaemia compared to moderate anaemia and those with mild anaemia showed the least increase. This pattern was common to both FCM and iron sucrose groups and was found to be statistically significant.

FCM showed a better symptomatic improvement compared to iron sucrose in common symptoms of anaemia like easy fatigability (78\% relief in FCM group and $62 \%$ in iron sucrose group) and headache (73\% showed improvement in FCM group and $57 \%$ in iron sucrose group). However, those who received iron sucrose showed better improvement in symptoms like loss of appetite.

Table 7: Comparison of average increase in $\mathrm{HB}$ based on the grade of anaemia.

\begin{tabular}{|lll|}
\hline $\begin{array}{l}\text { Grade of } \\
\text { anaemia }\end{array}$ & $\begin{array}{l}\text { Average } \\
\text { increase in HIB } \\
\text { in FCM group }\end{array}$ & $\begin{array}{l}\text { Average } \\
\text { increase in HBB } \\
\text { in is group }\end{array}$ \\
\hline Mild & 1.9 & 1.2 \\
\hline Moderate & 3 & 2 \\
\hline Severe & 3.6 & 2.8 \\
\hline
\end{tabular}

Disappearance of conjunctival pallor after 2 weeks was observed in $70 \%$ of the FCM group and $53 \%$ of iron sucrose group. Similar results were observed with lingual pallor. FCM was observed to be better in resolving other signs like nail and skin changes, tachycardia.

Table 8: Symptomatic improvement.

\begin{tabular}{|c|c|c|c|c|c|c|}
\hline Symptoms & $\begin{array}{l}\text { No. of cases with } \\
\text { the symptom in } \\
\text { FCM group }\end{array}$ & $\begin{array}{l}\text { Frequency of } \\
\text { improvement } \\
\text { in FCM group }\end{array}$ & $(\%)$ & $\begin{array}{l}\text { No. of cases with } \\
\text { the symptom in } \\
\text { iron sucrose group }\end{array}$ & $\begin{array}{l}\text { Frequency of } \\
\text { improvement in } \\
\text { iron sucrose group }\end{array}$ & $(\%)$ \\
\hline Easy fatigability & 23 & 18 & 78 & 21 & 13 & 62 \\
\hline Headache & 11 & 8 & 73 & 7 & 4 & 57 \\
\hline Giddiness & 6 & 5 & 83 & 6 & 4 & 67 \\
\hline Loss of appetite & 5 & 3 & 60 & 9 & 6 & 67 \\
\hline $\begin{array}{l}\text { Breathlessness/palp } \\
\text { itations }\end{array}$ & 2 & 1 & 50 & 3 & 2 & 67 \\
\hline
\end{tabular}

Table 9: Improvement with respect to signs.

\begin{tabular}{|c|c|c|c|c|c|c|}
\hline Signs & $\begin{array}{l}\text { No. of cases } \\
\text { with the sign in } \\
\text { FCM group }\end{array}$ & $\begin{array}{l}\text { Frequency of } \\
\text { disappearance } \\
\text { of sign }\end{array}$ & $(\%)$ & $\begin{array}{l}\text { No. of cases with } \\
\text { the sign in iron } \\
\text { sucrose group }\end{array}$ & $\begin{array}{l}\text { Frequency of } \\
\text { disappearance } \\
\text { of sign }\end{array}$ & $(\%)$ \\
\hline Conjunctival pallor & 40 & 28 & 70 & 38 & 20 & 53 \\
\hline Pale tongue & 40 & 30 & 75 & 44 & 24 & 55 \\
\hline Facial pallor & 15 & 10 & 67 & 16 & 10 & 63 \\
\hline Pale palmar creases & 14 & 9 & 64 & 14 & 7 & 50 \\
\hline Nail changes & 22 & 12 & 54 & 20 & 8 & 40 \\
\hline Skin changes & 3 & 1 & 33 & 4 & 1 & 25 \\
\hline Tachycardia & 13 & 10 & 77 & 15 & 9 & 60 \\
\hline Cardiac murmur & 1 & 1 & & 1 & 1 & \\
\hline
\end{tabular}

\section{DISCUSSION}

Postpartum anaemia being a major cause of morbidity and mortality in countries like India needs to be addressed with an effective solution. Infusion of injectable iron post-delivery gives us a better opportunity for anaemia correction with easy motivation and better compliance.
This study was devised to compare the efficacy of FCM and iron sucrose in terms of elevation of hb levels and symptomatic betterment and comprised of population of reproductive age group, mostly between 23 and 27 years of age. Half of them were home makers and the other half unskilled labourers. On classifying them based on laboratory values, about a half of them were moderately anaemic. They most commonly presented with 
complaints of easy fatigability (44\%) and signs of lingual and conjunctival pallor $(80 \%)$.

The average increase in laboratory haemoglobin (measured 2 weeks post infusion of $1000 \mathrm{mg}$ of injectable iron) was found to be $3.2 \mathrm{~g} \%$ in the FCM group and $2 \mathrm{~g} \%$ in the iron sucrose group in our study in contrast to the study conducted by Garag $\mathrm{R}$ et al wherein the increase in hb were $2.48 \mathrm{~g} \%$ and $2.1 \mathrm{~g} \%$ in the FCM group and iron sucrose group respectively. ${ }^{9}$ A study conducted by Shah $\mathrm{S}$ et al, showed an average increase of $2.52 \mathrm{~g} \%$ in $\mathrm{hb}$ following FCM infusion. ${ }^{10}$

FCM showed a better relief of common symptoms like headache and easy fatigability in comparison to iron sucrose. Similar results were obtained by many other studies wherein most of the women who were treated with FCM had an improved sense of wellbeing. FCM was also found to be superior in causing disappearance of signs of anaemia like pallor.

It was also seen that FCM had better acceptance by the subjects due to its easy administration (up to $1000 \mathrm{mg}$ in 15-20 $\mathrm{min}$ ) and decreased duration of stay in the hospital in contrast to iron sucrose which was given in 5 divided doses of $200 \mathrm{mg}$ each on alternate days requiring motivation for prolonged stay at the hospital or multiple visits to the OPD.

The cost of the FCM drug is relatively high when compared to other available parentral iron preparations like iron sucrose. This high cost of the drug would be compensated when the number of visits and number of days of hospital admission are considered. However, post-partum infusion of FCM in women with anaemia as part of the national programme for anaemia control would be of great value to Indian women. This would give us an opportunity to correct anaemia and also iron stores of several Indian women who had been chronically anaemic and would continue to be so even during the next pregnancy if left untreated.

Also, reduced frequency of venous access in case of FCM reduces the risk of infection and pain to the patient.

\section{CONCLUSION}

In a country like India where about a half of the women suffer from anaemia and it's complications post-partum, correction of anaemia through injectable iron seems an effective strategy due to better and predictable absorption, effective motivation and implementation during the woman's stay at the hospital and better compliance.
FCM was found to be better hand iron sucrose in terms of increasing the laboratory hb values as well as providing symptomatic relief in women with post-partum anaemia. It was also found to have better compliance and acceptability and hence should be considered a first line drug in managing post-partum anaemia and decreasing the huge burden of anaemia and its related morbidity and mortality.

\section{Funding: No funding sources \\ Conflict of interest: None declared}

Ethical approval: The study was approved by the Institutional Ethics Committee

\section{REFERENCES}

1. World Health Organization. Haemoglobin concentrations for the diagnosis of anaemia and assessment of severity. Vitamin and Mineral Nutrition Information System. 2011. Available at: http://www.who.int/vmnis/indicators/haemoglobin/en/. Accessed on $14^{\text {th }}$ June 2018.

2. Lokare PO. A study of prevalence of anemia and sociodemographic factors associated with anemia among pregnant women in Aurangabad city, India. Ann Nig Med. 2012;6(1):30-4.

3. Froessler B, Collingwood J, Hodyl NA, Dekker G. Intravenous ferric carboxymaltose for anaemia in pregnancy. BMC Preg Childbirth. 2014;14:115.

4. Bodnar LM, Siega-Riz AM, Miller WC, Cogswell ME, McDonald T. Who should be screened for postpartum anemia? An evaluation of current recommendations. Am J Epidemiol. 2002;156(903-12).

5. Milman N. Postpartum anemia I: definition, prevalence, causes and consequences. Ann Hematol. 2011;90:124753.

6. Friedrisch JR, Cancado RD. Intravenous ferric carboxymaltose for the treatment of iron deficiency anaemia. Rev Bras Hematol Hemoter. 2015;37(6):4005 .

7. Gautham KSK. Intravenous iron sucrose. World J Anaemia. 2017;1(1):20-2.

8. Rudra S, Chandna A, Nath J. Comparison of intravenous iron sucrose with oral iron in pregnant women with iron deficiency anaemia. Int J Reprod Contracept Obstet Gynecol. 2016;5(3):747-51.

9. Garg R, Nigam A, Agrawal P, Nigam A, Agrawal R. Iron carboxymaltose: a safe and effective molecule to combat anaemia in pregnancy. Int J Curr Res Aca Rev. 2016;4(2):124-30.

10. Shah S. A comparative study of efficacy and safety of intravenous ferric carboxymaltose versus intravenous iron sucrose in the treatment of iron deficiency anaemia of pregnancy. IOSR J Dent Med Sci. 2018;17(9):13-7.

Cite this article as: Garag SS, Kumar S. A comparative study between ferrous carboxy maltose and iron sucrose in the management of post-partum anaemia in tertiary care hospital. Int J Reprod Contracept Obstet Gynecol 2019;8:4866-70. 